九州大学学術情報リポジトリ

Kyushu University Institutional Repository

\title{
Lactic Acid Recovery from Model Solutions and Fermentation Broth by Electrodialysis
}

Nolasco-Hipolito, Cirilo

Department of Food Science and Technology, Graduate School of Bioresource and Bioenvironmental Sciences, Kyushu University

Thang, Vu Hong

Department of Food Biotechnology, Hanoi University of Technology

Kobayashi, Genta

Laboratory of Microbial Technology, Department of Bioscience and Biotechnology, Faculaty of Agriculture, Graduate School, Kyushu University

Sonomoto, Kenj i

Laboratory of Microbial Technology, Department of Bioscience and Biotechnology, Faculaty of Agriculture, Graduate School, Kyushu University

他

https://doi.org/10.5109/24404

出版情報: 九州大学大学院農学研究院紀要. 45 (2)，pp.531-541，2001-02-28. Kyushu University バージョン：

権利関係: 
J. Fac. Agr., Kyushu Univ., 45 (2), 531-540 (2001)

\title{
Lactic Acid Recovery from Model Solutions and Fermentation Broth by Electrodialysis
}

\author{
Cirilo Nolasco-Hipolito*, Vu Hong Thang**, Genta Kobayashi, Kenji \\ Sonomoto*** and Ayaaki Ishizaki
}

\author{
Laboratory of Microbial Technology, Department of Bioscience and Biotechnology, \\ Faculty of Agriculture, Graduate School, Kyushu University, \\ Fukuoka 812-8581 \\ (Received October 27, 2000 and accepted November 10, 2000)
}

\begin{abstract}
The effect of current density, initial concentration of diluting solution on lactic acid (LA) recovery by electrodialysis from both model solutions and real fermentation broth was investigated. In model solutions, LA recovery efficiency was $93-96 \%$ and it was independent of both, current density and initial concentration of diluting solution. The recovery rates at 33,66 and $100 \mathrm{~A} \cdot \mathrm{m}^{-2}$ were 76,175 and $272 \mathrm{~g} \cdot \mathrm{m}^{-2} \cdot \mathrm{h}^{-1}$ respectively and, clearly were linearly depended on current density. In the first stage of the process, both model solution and real fermentation broth showed similarities in the dynamic of LA recovery and water flux. With real fermentation broth, at current density of $100 \mathrm{~A} \cdot \mathrm{m}^{-2}$ and $41.8 \mathrm{~g} / \mathrm{l}$ initial lactate concentration of diluting solution, the LA recovery rate and the water flux were 279.5 and $679 \mathrm{~g} \cdot \mathrm{m}^{-2} \cdot \mathrm{h}^{-1}$, respectively. However, the recovery efficiency was decreased from a $93-96 \%$ range to $71 \%$, compared to that in model solutions. The reason probably was that anion-exchange membrane was fouled by protein from broth.

Keywords: lactic acid recovery, electrodialysis, ion exchange membrane, model solution, fermentation broth.
\end{abstract}

\section{INTRODUCTION}

Lactic acid fermentation (LAF) is one of the most important microbial processes because it is used widely in numerous fields of application as food, pharmaceutical industries and because it has great potential in the manufacture of biodegradable polymers and films (Datta et al., 1995).

LA can be separated from the fermentation broth by dialysis (Pörtner and Märkl, 1998), ion-exchange resin (Srivastava et al., 1992; Vaccari et al., 1993) and extraction (Honda et al., 1995; Von Frieling and Schügerl, 1999). Separation by dialysis has the disadvantage of requiring dilute product stream to effect reasonable mass transfer rate aside from the need to convert LA into salt prior to removal (Pörtner and Märkl, 1998). Extraction needs solvents, many of which were found toxic to both acid-producing

\footnotetext{
* Department of Food Science and Technology, Graduate School of Bioresource and Bioenvironmental Sciences, Kyushu University, Fukuoka 812-8581

** Department of Food Biotechnology, Hanoi University of Technology, 1 Dai Co Viet Street, Hanoi, Vietnam

*** Corresponding author (sonomoto@agr.kyushu-u.ac.jp)
} 
microorganisms and environment (Hongo et al., 1986; Von Frieling and Schügerl, 1999)

The main disadvantage is that fermentation derived sodium lactate, which was formed during the fermentation through the addition of $\mathrm{NaOH}$ to maintain the $\mathrm{pH}$ of fermentation broth stable is difficult and expensive to purify (Boniardi et al., 1997). Much of the cost of LA production has been associated with the recovery and purification processes. In the past, efficient and economical technologies for recovery and purification of LA from crude fermentation broth had been the key technology impediments and main process cost centers (Datta et al., 1995). Among the other processes, electrodialysis is promising for the downstream processing in LAF.

Recently, electrodialysis was considered as a desalination process to be applied to such solution as brackish water and seawater (Jain et al., 1985). In particular, electrodialysis can be used as alternative to the downstream processes to recover pollutants from industrial effluent (Andrés et al., 1994). In biotechnology, electrodialysis was used to remove continuously not only lactic (Hongo et al., 1986; Ishizaki et al., 1990; Yao and Toda, 1990), but also acetic (Nomura et al., 1988), propionic (Voyabal et al., 1993) and itaconic (Moresi and Sappino 2000) acids from fermentation broth, in order to enhance microbial acidic productivity and make the final processing easier. In these systems, LA can be recovered either as an acid (Hongo et al., 1986; Yao and Toda, 1990) or as a lactate salt (Vonktaveesuk et al. 1994) diffusing through ion-exchange membranes under supplied direct current.

In our laboratory, $\mathrm{L}-(+)$ - LA has been produced from sago starch hydrolyzed in an environmentally sound bioprocess with high efficiency. Thus, an environmentally friendly downstream process, such as electrodialytic application, for recovery and purification of LA produced is needed. In this study, the recovery of LA from model solution and fermentation broth by electrodialysis was discussed.

\section{MATERIALS AND METHODS}

\section{Microorganisms and culture conditions}

Microorganism. Lactococcus lactis IO-1 was used throughout this study.

Culture conditions. Culture conditions were carried out as described previously (Ishizaki and Ohta, 1989).

Sago starch hydrolysis. Sago starch hydrolysis was carried out as described previously (Nolasco-Hipolito et al., 2000).

Fermentation. After $3 \mathrm{~h}$ of incubation, $40 \mathrm{ml}$ of prepared preculture was aseptically inoculated with $360 \mathrm{ml}$ of main medium in a $1 l$-jar fermentor. The main medium contained $(\mathrm{g} / \mathrm{l})$ : polypeptone (Nihon Seiyaku, Tokyo, Japan), 10; yeast extract (Difco Laboratories, Detroit, MI, USA), 10; NaCl, 5; and glucose from hydrolyzed sago starch, 40.

Analysis. Glucose and lactate concentrations were determined by HPLC (LC $-10 \mathrm{AD}, \mathrm{RID}-6 \mathrm{~A}$ Refractive Index Detector, Shimadzu, Kyoto, Japan) using an Aminex $\mathrm{HPX}-87 \mathrm{H}$ column (Bio-Rad Laboratories, CA, USA) at $50{ }^{\circ} \mathrm{C}$ and $0.6 \mathrm{ml} / \mathrm{min}$ flow rate of $5 \mathrm{mM} \mathrm{H}_{2} \mathrm{SO}_{4}$ as a mobile phase. Cell density was measured in terms of optical density, at $562 \mathrm{~nm}$, in a spectrophotometer (UVIDEC-320 Spectrophotometer, Jasco Co., Tokyo, Japan) and converted to dry cell weight (DCW) from calibration curve. 


\section{Apparatus for electrodialysis}

Experimental set-up for electrodialysis system is shown in Figure 1; which consists in a five-compartments electrodialyzer: cathode, anode, concentrated and two diluted compartments. Each compartment was separated by cation and anion exchange membranes. The electrodialyzer was provided two anion exchange (Neosepta AM1) membranes and two cation exchange (Neosepta CM1) membranes (both from Tokuyama Co., Tokyo, Japan). The cathode and anode were made of platinum. The process flow sheet is shown in Figure 1 with four independent streams: the electrode solution was supplied by the same stream to both cathode compartment and anode compartment, while three other solutions were recirculated independently in concentrated compartment and two diluted compartments. Starting from the reservoirs, each solution was pumped through the compartment and then returned to the respective reservoir until the electrodialysis finished.

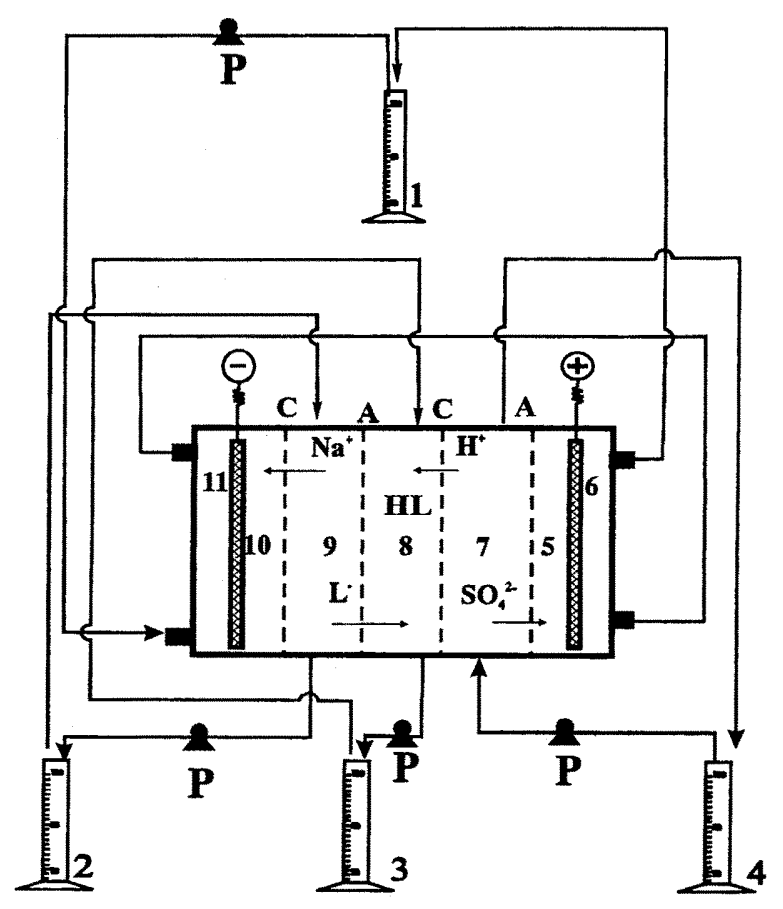

Fig. 1. Schematic diagram of the electrodialyzer. L-: lactate ion; HL: lactic acid; C: cation-exchange membrane; A: anion-exchange membrane; P: pump; $(-)$ : cathode; $(+)$ : anode. 1: $3 \% \mathrm{Na}_{2} \mathrm{SO}_{4}$ solution; 2 : sodium lactate solution; 3: concentrated solution; 4: $0.2 \mathrm{M} \mathrm{H}_{2} \mathrm{SO}_{4}$; 5 : anode compartment; 6 : anode; 7\&9: diluted compartments; 8: concentrated compartment; 10: cathode compartment; 11: cathode. 
To determine the volume variations generated during the electrodialysis process, reservoirs with scale resolution $\pm 2 \mathrm{ml}$ accuracy were used. Direct current was supplied by a power unit (NISC Regulated DC Power Supply, Stabilizer Industry, Osaka, Japan). This power unit employed can be set independently either the voltage in the range of $0-35 \mathrm{~V}$, or the current in the range of 0-2 A. All experiments were carried out in constant current values and would be stopped when the voltages reached $35 \mathrm{~V}$. In all experiment runs, the initial volume of all solution were $500 \mathrm{ml}$.

Solutions of sodium lactate, $0.2 \mathrm{M} \mathrm{Na}_{2} \mathrm{SO}_{4}$ and $0.2 \mathrm{M} \mathrm{H}_{2} \mathrm{SO}_{4}$ were used. The former and the latter were recirculated in two dilute compartments respectively while solution of $\mathrm{Na}_{2} \mathrm{SO}_{4}$ was supplied for both cathode and anode compartment. Water was used for recirculation in concentrated compartment. Initial volumes of all solution were $500 \mathrm{ml}$, except in the case of concentrated compartment, the initial volume of water was just enough to fill up the compartment. Before running every experiment, membranes were cleaned in situ by recycling a $0.05 \mathrm{M} \mathrm{HCl}$ solution during $1 \mathrm{~h}$, followed by a $0.05 \mathrm{M} \mathrm{NaOH}$ solution and then $\mathrm{HCl}$ again. Finally, the system was rinsed by deionized water.

\section{RESULTS AND DISCUSSION}

\section{Effect of current density}

The current density plays an important role in electrochemical process, where current is the driven force for the transport of ionic species. In the separation of electrochemical process such as electrodialysis, it was found that the transport of ionic species is decided not only by both, properties of that species and type of membranes, but also by current density (Moon et al., 1993). Experiments were carried out by using the same $40 \mathrm{~g} / \mathrm{l}$ initial concentration of sodium lactate. During electrodialysis process, the concentration of sodium lactate and $\mathrm{H}_{2} \mathrm{SO}_{4}$ in diluting compartments decreased, and the electric resistance in the electrodialyzer unit increased. Therefore, the direct current supplier had to increase automatically the voltage applied to electrodes up to value of $35 \mathrm{~V}$ to maintain the current density constant. This operation was called the constant-current mode (Lee et al., 1998). After reaching the maximum value of $35 \mathrm{~V}$ the current began to decrease. All experiments were practically stopped at that moment to avoid damage membranes by overheat phenomenon. Especially, after finish the constant current mode, the LA recovery efficiency was decreased and the LA concentration in the concentrated solution changed very slow (data not shown). For this reason, it had better to operate electrodialysis in the constant-current mode when electrodialyzer would be combined with a fermentation system to remove continuously lactate produced. Figure 2 shows the time course of lactate ion recovery from salt form into acid form. As expected, the lower the current density value applied the longer the process time needed to separate LA. At three different current densities: 33,66 and $100 \mathrm{~A} \cdot \mathrm{m}^{-2}$, the LA recovery rates were 76,175 and $272 \mathrm{~g} \cdot \mathrm{m}^{-2} \cdot \mathrm{h}^{-1}$, respectively. The LA recovery was practically finished within 19,8 and $6 \mathrm{~h}$, respectively. At the high current density $\left(100 \mathrm{~A} \cdot \mathrm{m}^{-2}\right)$ the electrodialysis operated in the constant current mode while the residual sodium lactate in diluting compartment was being maintained higher than 5\% (in comparison with the initial sodium lactate) or lactate concentration in diluting compartment lower than $5 \mathrm{~g} / \mathrm{l}$ (4.1-4.4 g/l). This value of switching concentration was lower than that obtained by Lee, 


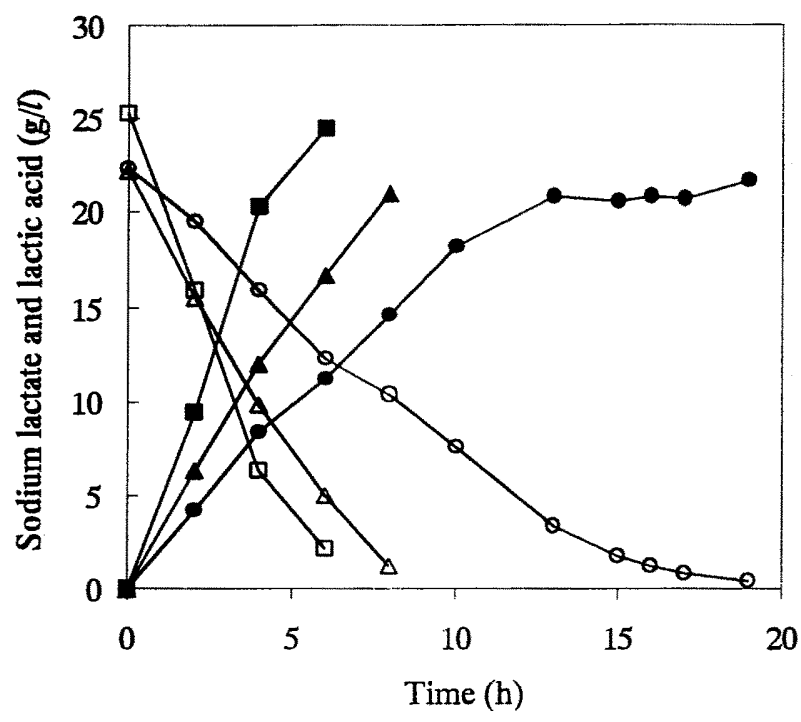

Fig. 2. Time course of the recovery of sodium lactate by electrodialysis containing $40 \mathrm{~g} / \mathrm{l}$ of lactate at different current densities; symbols: $33 \mathrm{~A} \cdot \mathrm{m}^{-2}(\boldsymbol{O}, \mathrm{O}), 66 \mathrm{~A} \cdot \mathrm{m}^{-2}(\boldsymbol{\Delta}, \Delta)$, $100 \mathrm{~A} \cdot \mathrm{m}^{-2}(\square, \square)$. Closed symbols: LA recovered. Open symbols: LA equivalent (salt form).

et al. (1998) when they finished the constant-current mode at switching concentration of lactate in diluted compartment was being remained about $10 \%$ (lactate concentration was about $11 \mathrm{~g} / \mathrm{l}$ ), even they used low current densities, in a range of $35-45 \mathrm{~A} \cdot \mathrm{m}^{-2}$. The results obtained showed that the lower the current densities, the lower the values of switching concentration. At current densities of $66 \mathrm{~A} \cdot \mathrm{m}^{-2}$ and $33 \mathrm{~A} \cdot \mathrm{m}^{-2}$, the final lactate concentration in diluting compartment was 2.4 and $0.8 \mathrm{~g} / l$, respectively. During the constant-current mode, the LA recovery rate was almost linearly dependent on current density. After that, recovery rate decreased because the electric resistance increased due to the removing of ions in diluting compartments. From this result, it can be expected to maintain the lactate concentration in fermentation broth at a level low if the electrodialyzer is installed so that its capability of converting lactate ion is in agreement with the lactic acid production rate in the fermentation system. However, the recovery efficiency of LA did not depend on current density. It was found that there was no influence of the current density on the recovery efficiency, in the case of the same initial lactate concentration. Approximately $93-96 \%$ of recovery efficiency was obtained in all three different current densities.

During the transport of ionic species, some hydration water molecules bound to ions also diffused with ions through membranes. This phenomenon was called electro-osmosis and generates an increase in the volume of the concentrated solution, and a simultaneous decrease in that of the diluting solutions. Figure 3 shows the volume 


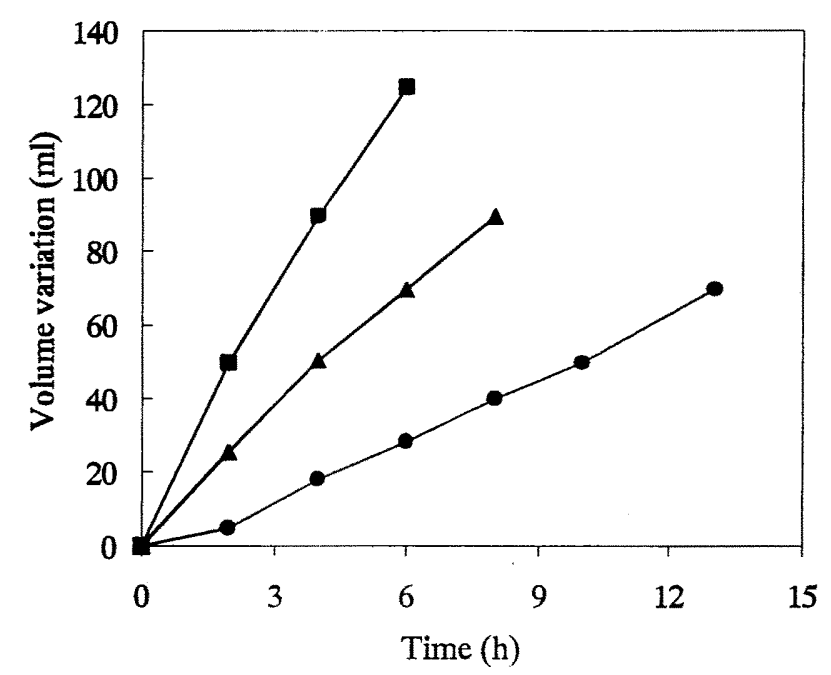

Fig. 3. Volume variation of concentrated solution as a function of time at different current densities; symbols: (O), $33 \mathrm{~A}$. $\left.\mathrm{m}^{-2} ;(\mathbf{A}), 66 \mathrm{~A} \cdot \mathrm{m}^{-2} ; \mathbf{(}\right), 100 \mathrm{~A} \cdot \mathrm{m}^{-2}$.

variations in the concentrated solution against the time. After the first hour of the operation, it seems that the volume variations in the concentrated solution increased proportionally with the time and depend linearly on current density. At the beginning of the electrodialysis, the water flux ${ }^{(1)}$ was slow because the concentration of LA in the concentrated compartment was still very low and this caused the limitation of the ion transportation. The increase in current density resulted in an increase the water flux. At three different current densities: 33,66 and $100 \mathrm{~A} \cdot \mathrm{m}^{-2}$, the water fluxes were 235,458 and $667 \mathrm{~g} \cdot \mathrm{m}^{-2} \cdot \mathrm{h}^{-1}$, respectively. However, these water fluxes would limit the maximum LA concentration achievable. From the results obtained in water flux and LA recovery rate, it is possible to estimate the maximum LA concentration achievable to be about $407 \mathrm{~g} / l$. This result was similar to that obtained by Boniardi, et al. (1997).

It can be seen from Figure 4 that the volume variation trend in the sodium lactate solution was similar to that in the concentrated solution. Higher current density caused the higher volume variation of sodium lactate solution. At three different current densities: 33,66 and $100 \mathrm{~A} \cdot \mathrm{m}^{-2}$, the volume variations of sodium lactate solution were 359 , 750 and $1042 \mathrm{~g} \cdot \mathrm{m}^{-2} \cdot \mathrm{h}^{-1}$, respectively. However, at the same current density, the volume variation of sodium lactate solution was from 1.42 to 1.64 times greater than that of the concentrated solution.

(1) Water flux: Average of the absolute volume variation due to water transfer into concentrated compartment, gram per unit cell pair surface area and time $\left(\mathrm{g} \cdot \mathrm{m}^{-2} \cdot \mathrm{h}^{-1}\right)$ 


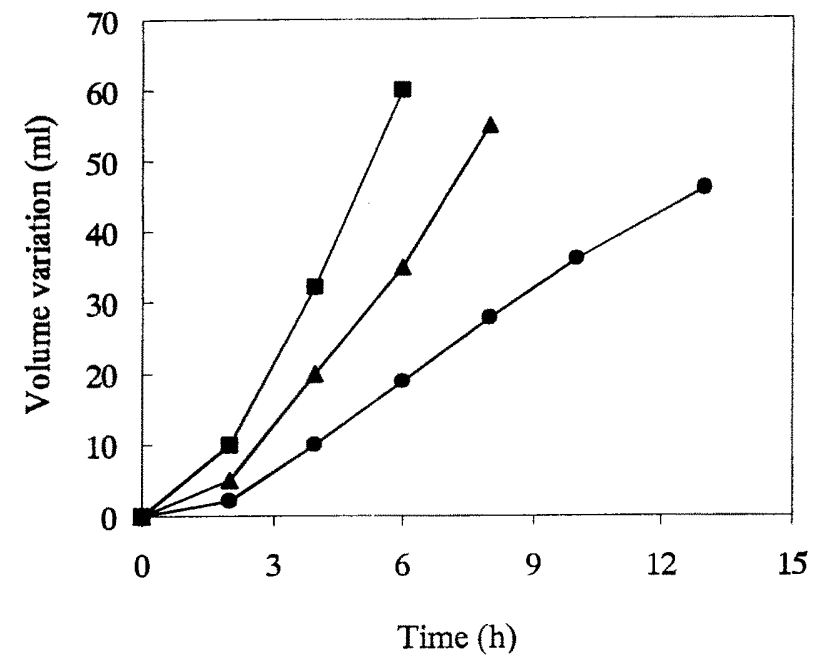

Fig. 4. Volume variation of sodium lactate solution as a function of time at different current densities; symbols: (O), $33 \mathrm{~A} \cdot$ $\mathrm{m}^{-2} ;(\mathbf{A}), 66 \mathrm{~A} \cdot \mathrm{m}^{-2} ;$ () $), 100 \mathrm{~A} \cdot \mathrm{m}^{-2}$.

\section{Effect of initial concentration of sodium lactate on the lactic acid recovery}

The influence of the initial concentration of sodium lactate was investigated in three different values: 40,60 and $86.4 \mathrm{~g} / \mathrm{l}$. The main reason for this choice was the final lactate concentrations in most of fermentation systems reported so far are lower than $90 \mathrm{~g} / l$ (Hofvendahl and Hahn-Hägerdal 2000). The effect of the initial sodium lactate concentration on the LA recovery is shown in Figure 5. The data obtained showed that there was no influence of the initial concentration of sodium lactate. It can be seen from this figure that all experimental points representing the LA recovered lay almost around a straight line and all lines representing sodium lactate converted are parallel (with the same slope). This means both the LA recovery rate and converted lactate rate did not change. However, higher initial concentration of sodium lactate caused longer time process. In all runs, the LA recovery rates were approximately $93-96 \%$. The volume variation of the concentrated solution was investigated and it was found that the initial concentration of sodium lactate had no influence on the water fluxes (data not shown).

\section{Electrodialysis of fermentation broth}

The electrodialysis of real fermentation broth was conducted to compare with the observations made using above model solutions. The results obtained by using electrodialysis to recover LA from real fermentation broth are reported in Table 1 and shown in Figure 6. During the three first hours, the lactate recovery rate was almost maintained the same value comparing with that obtained in model solution. However, after that the recovery rate was significantly decreased and the overall recovery efficiency fell from a 93-96\% range, observed in model solutions, to $71 \%$ (Table 1 ). The process time in the 


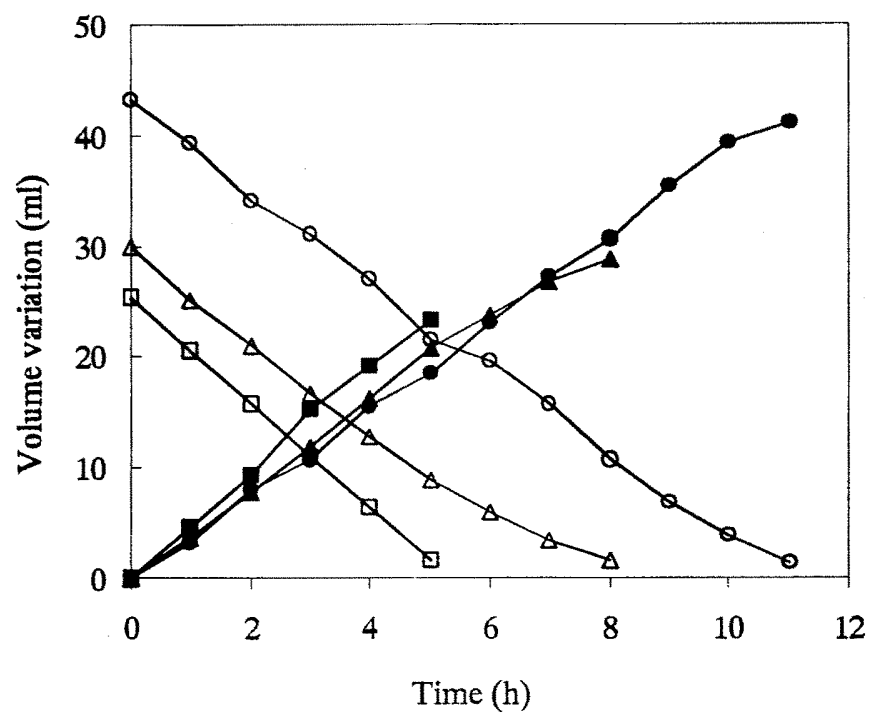

Fig. 5. Time course of the recovery of sodium lactate by electrodialysis at the same current density $\left(100 \mathrm{~A} \cdot \mathrm{m}^{-2}\right)$; symbols: $(\mathbf{O}, \mathrm{O})$, initial concentration of $86.4 \mathrm{~g} / l ;(\boldsymbol{\Delta}, \triangle)$, initial concentration of $60 \mathrm{~g} / l ;(\square, \square)$, initial concentration of $40 \mathrm{~g} / l$. Closed symbols: LA recovered. Open symbols: LA equivalent (salt form).

constant-current mode was $6 \mathrm{~h}$, similar to that observed in model solution, but the electrodialysis was only operated in the constant-current mode until the sodium lactate concentration in diluting compartment reached the level of $13 \mathrm{~g} / l$. The reason could be that the presence of complex compounds in the broth affecting the electrodialysis. It was found that some electrical charge compounds (e.g. proteins), adhered to anion-exchange membrane. This would limit the transport of lactate ion through the membrane. The water flux of $679 \mathrm{~g} \cdot \mathrm{m}^{-2} \cdot \mathrm{h}^{-1}$, was not significantly different from the value of $667 \mathrm{~g} \cdot \mathrm{m}^{-2} \cdot \mathrm{h}^{-1}$, obtained in model solution. The LA recovery was practically finished within $6 \mathrm{~h}$.

Unlike many previous electrodialysis units, in this electrodialysis system LA was formed by indirect reaction between sodium lactate and $\mathrm{H}_{2} \mathrm{SO}_{4}$. Vonktaveesuk et al. (1994) studied fermentation system using electrodialysis unit to remove lactate from broth, however, the final product was sodium lactate not LA. Earlier, Hongo et al. (1986) and Nomura et al. (1988) used electrodialysis to control the fermentation and to remove directly LA from broth but it was very difficult to maintain $\mathrm{pH}$ stable for long time. Moreover, it was found that the rate of LA production was greatly improved by converting LA produced to sodium lactate and continuously removing this salt from the fermentation broth. In addition, they could not maintain the optimum $\mathrm{pH}$ of the broth by the electrodialysis of sodium lactate (Yao and Toda, 1990). The reason could be that the LA production rate overcame conversion capability of the electrodialyzer. Therefore the system. reported in this study possesses some advantages over others reported before, because 


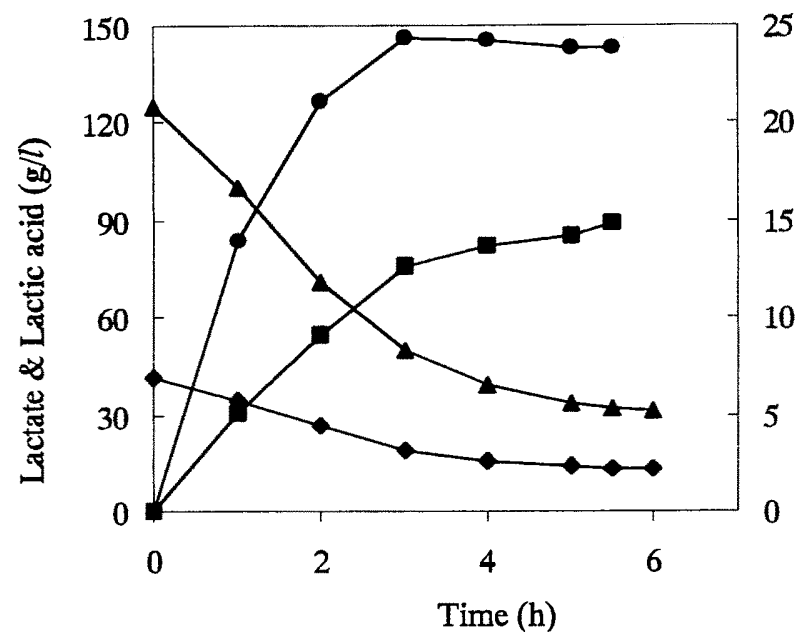

Fig. 6. Time course of the LA recovery from fermentation broth by electrodialysis at current density of $100 \mathrm{~A} \cdot \mathrm{m}^{-2} ; 41.8 \mathrm{~g} / \mathrm{l}$ initial lactate concentration in broth. Symbol: (O), LA in the concentrated solution; ( $\mathbf{D})$, LA recovered; $(\boldsymbol{\Delta})$, Sodium lactate consentration in broth; $(\bullet)$, residual lactate in the broth.

Table 1. Comparison of LA recovery by electrodialysis at different conditions

\begin{tabular}{|c|c|c|c|c|c|c|c|c|}
\hline Exp. & $\begin{array}{l}\text { Current } \\
\text { density, } \\
\left(\mathrm{A} \cdot \mathrm{m}^{-2}\right)\end{array}$ & $\begin{array}{l}\text { Initial } \\
\text { feed } \\
\text { conc., } \\
(\mathrm{g} / \mathrm{l})\end{array}$ & $\begin{array}{c}\text { Switching } \\
\text { conc., } \\
(\mathrm{g} / \mathrm{l})\end{array}$ & $\begin{array}{c}\text { Operating } \\
\text { time, } \\
(h)\end{array}$ & $\begin{array}{l}\text { Final LA } \\
\text { conc. } \\
\text { recovered, } \\
(\mathrm{g} / \mathrm{l})\end{array}$ & $\begin{array}{c}\text { LA } \\
\text { recovery } \\
\text { efficiency, } \\
\%\end{array}$ & $\begin{array}{c}\text { Water } \\
\text { flux, } \\
\left(\mathrm{g} \cdot \mathrm{m}^{-2} \cdot \mathrm{h}^{-1}\right)\end{array}$ & $\begin{array}{c}\text { LA } \\
\text { recovery } \\
\text { rate, } \\
\left(\mathrm{g} \cdot \mathrm{m}^{-2} \cdot \mathrm{h}^{-1}\right)\end{array}$ \\
\hline 1 & 100 & 40 & 4.3 & 6 & 222.6 & 96.84 & 667 & 272 \\
\hline 2 & 100 & 60 & 4.1 & 9 & 193.7 & 97.07 & - & - \\
\hline 3 & 100 & 86.4 & 4.4 & 11 & 210.5 & 95.28 & - & - \\
\hline $4^{*}$ & 100 & 41.8 & 13.1 & 6 & 146.0 & 70.89 & 679 & 279.5 \\
\hline 5 & 66 & 40 & 2.4 & 8 & 210.3 & 94.56 & 458 & 175 \\
\hline 6 & 33 & 40 & 0.8 & 19 & 196.9 & 96.87 & 235 & 76 \\
\hline
\end{tabular}

* Experiment with real fermentation broth. LA=lactic acid; conc.=concentration.

the possibility to obtain directly the final product as LA, would reduce the cost of the downstream process and would greatly enhance the competitiveness of fermentative lactic acid fermentation.

In this study, the capability of converting sodium lactate into LA by using electrodialysis was investigated. From the results obtained, it is possible to design a suitable 
electrodialyzer so that its capability can correspond to the productivity of fermentation system. Studies to solve the problem of fouling anion-exchange membrane and to completely make a continuous fermentation system with product recovery by electrodialysis are in progress.

\section{REFERENCES}

Andrés, L. J., F. A. Riera, R., Alvarez and R. Audinos 1994 Separation of strong acids by electrodialysis with membranes selective to monovalent ions. The Can. J. Chem. Eng., 72: 848-853

Boniardi, N., R. Rota, G. Nano and B. Mazza 1997 Lactic acid production by electrodialysis. Part 1: experimental tests. J. Appl. Electrochem., 27: 125-133

Boyaval, P., J. Seta and C. Gavach 1993 Concentrated propionic acid production by electrodialysis. Enz. Microb. Technol., 15: 683-686

Choi, J. I. and W. H. Hong 1999 Recovery of lactic acid by batch distillation with chemical reactions using ion exchange resin. J. Chem. Eng. Japan. 32: 184-189

Datta, R., S. P. Tsai, P. Bonsignore, S. H. Moon and J. R. Frank 1995 Technological and economic potential of poly lactic acid and lactic acid derivatives. FEMS. Microbiol. Rev., 16: 221-231

Hofvendahl, K. and B. Hahn-Hägerdal 2000 Factors affecting the fermentative lactic acid production from renewable resources. Enz. Microb. Technol., 26: 87-107

Honda, H., Y. Toyama, H. Takahashi, T. Nakazekeo and T. Kobayashi 1995 Effective lactic production by two-stage extractive fermentation. J. Ferment. Bioeng., 79: 589-593

Hongo, M., Y. Nomura and M. Iwahara 1986 Novel method of lactic acid production by electrodialysis fermentation. Appl. Environ. Mircobiol., 52: 314-319

Ishizaki, A., Y. Nomura and M. Iwahara 1990 Built-in electrodialysis batch culture, a new approach to release of end-product inhibition. J. Ferment. Bioeng., 70: 108-113

Ishizaki, A. and T. Ohta 1989 Batch culture kinetics of L-lactate fermentation employing Streptococcus sp. IO-1. J. Ferment. Bioeng., 67: 46-51

Jain, S. M. and P. B. Reed 1985 Electrodialysis. In: "Comprehensive Biotechnology", Vol. 2, ed. by C.L, Cooney. and A. E. Humphrey, Pergamon Press Ltd., New York, pp. 575-590

Lee, E. G., S. H. Moo, Y. K. Chang, I. K. Yoo and H. N. Chang 1998 Lactic acid recovery using two-stage electrodialysis and its modeling. J. Membr. Sci., 145: 53-66

Moon, P. J., S. J. Parulekar and S. P. Tsai 1998 Competitive anion transport in desalting of mixtures of organic acids by batch electrodialysis. J. Membr. Sci., 141: 75-89

Moresi, M. and F. Sappino 1998 Effect of some operating variables on citrate recovery from model solutions by electrodialysis. Biotechnol. Bioeng., 59: $344-350$

Moresi, M. and F. Sappino 2000 Electrodialytic recovery of some fermentation products from model solutions: techno-economic feasibility study. 164: J. Membr. Sci., 145: 53-66

Nolasco-Hipolito, C., E. Crabbe, G. Kobayashi, K. Sonomoto and A. Ishizaki 2000 pH-Dependent continuous lactic acid fermentation by Lactococcus lactis IO-1 using hydrolyzed sago starch. $J$ Fac Agr Kyushu Univ., 44: 367-375

Nomura, Y., M. Iwahara and M. Hongo 1988 Acetic acid production by an electrodialysis fermentation method with a computerized control system. Appl. Environ. Microbiol., 54: 137-142

Pörtner, R. and H. Märkl 1998 Dialysis culture. Appl. Microbiol. Biotechnol., 50: 403-414

Srivastava, A., P. Roychoudhury and V. Sahai 1992 Extractive lactic acid fermentation using ion-exchange resin. Biotechnol. Bioeng., 39:607-613.

Vaccari, G., R. A. Gonzales-Vara, A. L. Campi, E. Dosi, P. Brigidi and D. Matteuzzi 1993 Fermentative production of L-lactic acid by Lactobacillus casei DSM 20011 and product recovery using ion exchange resins. Appl. Microbiol. Biotechnol., 40: 23-27

Vonktaveesuk, P., M. Tonokawa and A. Ishizaki 1994 Stimulation of the rate of L-lactate fermentation using Lactococcus lactis 1O-1 by periodic electrodialysis. J. Ferment. Bioeng., 77: 508-512

Von Frieling, P. and K. Schügerl 1999 Recovery of lactic acid from aqueous model solutions and fermentation broth. Process Biochem, 34: 685-696

Yao, P. X. and K. Toda 1990 Lactic acid production in electrodialysis culture. J. Gen. Appl. Microbiol., 36: $111-125$ 